\title{
LA FISURA DE LAS TEXTUALIDADES: LA BRECHA DE MERCEDES VALDIVIESO
}

\author{
Mónica Barrientos \\ Universidad Autónoma de Chile \\ Grupo de Investigación en Literatura y Escuela (LyE) \\ Santiago, Chile \\ monica.barrientos@uautonoma.cl
}

RESUMEN / ABSTRACT

En la novela La brecha (1961) de Mercedes Valdivieso ingresamos al mundo íntimo de la voz sin nombre de una mujer de la alta sociedad chilena que se queja, como afirma el prólogo de Fernando Alegría, con una "descarnada franqueza" (cit. en Valdivieso, La brecha 11). A Alegría le conmueve la novela en el sentido que lo remece: no tiene antecedentes de la autora, no puede definir su estilo, no hay retórica, ni enredos de pasión; tampoco tiene claro el rumbo, ya que la historia no tiene un fin y "seguirá moviéndose entre seres reales y sombras de seres, buscando su camino" (ibid.). Es precisamente este modo de habitar el espacio por medio del movimiento lo que intentaré abordar en el análisis de esta novela. La propuesta de lectura abordará tres aproximaciones desde la figura del espacio en La brecha. En primer lugar, analizaremos los espacios institucionales (de la familia y el matrimonio) y de qué manera se van movilizando hacia un proceso de desnaturalización de su distribución asociados a los roles de género. Para ello, es necesario considerar las relaciones de poder que construyen reglas y fijan límites o coordenadas, ya sea espaciales o corporales, que controlan los procesos de inclusión y exclusión. En segundo lugar, analizaremos los espacios escriturales o, lo que Alegría llamó "retórica vacía", que permite crear "la brecha" para la fisura de estos espacios vigilados. Y, finalmente, veremos el proceso de conciencia de la voz narrativa por medio del concepto de "ensayos de género".

Palabras Clave: La brecha, Mercedes Valdivieso, conciencia feminista, ensayos de género.

THE FISSURE OF TEXTUALITIES:

LA BRECHA BY MERCEDES VALDIVIESO

La brecha (1961) by Mercedes Valdivieso enters the intimate world of the nameless voice of a woman from the Chilean high society who complains, as Fernando Alegria's prologue 
states, with "stark frankness" (11). Alegria is moved by the novel in the sense that it shakes him: he has no background on the author, he cannot define her style, there is no rhetoric, no entanglements of passion; nor is his course clear, since the story has no end and "will continue to move between real beings and shadows of beings, searching for its path" (ibid.). It is precisely this way of inhabiting space through movement that I will attempt to address in the analysis of this novel. The reading proposal will address three approaches from the figure of space in La brecha. First, we will analyze the institutional spaces (family, marriage) and how they are mobilized towards a process of denaturalization of their distribution associated with gender roles. For this, it is necessary to consider the power relations that construct rules and set limits or coordinates, whether spatial or corporal, that control the processes of inclusion and exclusion. Secondly, we will analyze the scriptural spaces or, what Alegria called an "empty rhetoric", which allows us to create "the gap" for the fissure of these guarded spaces. And finally, we will look at the process of consciousness of the narrative voice through the concept of "gender essays".

KEYWORDS: La brecha, Mercedes Valdivieso, feminist conscience, gender essay.

Recepción:12/07/2021

Aprobación: 27/08/2021

Pero hubo un instante, hubo una decisión, hubo un acto en que la mujer alcanzó a conciliar su conducta con sus apetencias más secretas, con sus estructuras más verdaderas, con su última instancia. Y en esa conciliación su existencia se insertó en el punto que le corresponde en el universo, evidenciándose como necesaria y resplandeciendo de sentido, de expresividad, de hermosura.

Rosario Castellanos, Mujer que sabe latín

La literatura escrita por mujeres en Latinoamérica venía desarrollando, a partir de los sesenta - hay excepciones a la regla- un trabajo más expuesto y "profesionalizante" de la escritura. Como ha sido ampliamente estudiado por la crítica de la generación del $50^{1}$, este es un periodo en el que aparecen una serie de escritores en diferentes publicaciones que, con el paso del tiempo, se

1 No profundizaremos en la polémica sobre esta generación que tiene una amplia discusión no zanjada de la crítica sobre las fechas, las características y las perspectivas de este grupo. Para mayor detalle, véase el libro La generación del 50 en Chile: historia de un movimiento literario (narrativa) (1992) de Eduardo Godoy, Eduardo, Haydée Ahumada Peña y Carlos Díaz Amigo. 
convirtieron en los referentes de la literatura nacional ${ }^{2}$. Junto con explicar el concepto de "generación" y los criterios metodológicos definen, como uno de los rasgos que caracteriza a este grupo, el "escepticismo radical frente a la vida y a la literatura anterior"3 (Godoy et al. 16), lo que se entiende como falta de atención a los problemas sociales y una focalización en temas individuales o íntimos debido a los profundos cambios en la sociedad después de la guerra, como afirma José Promis:

el mundo que se desploma no es el de una clase social -como ha repetido insistentemente la crítica- ni una forma política, ni un estado histórico particular y limitable nacionalmente; es un momento de la existencia humana que llega a su fin, dejando a su paso el producto vacío de lo que ya existe (152).

Sin embargo, este "escepticismo radical" (Godoy et al. 17), aun cuando Promis no quiera relacionarlo con la coyuntura social ${ }^{4}$, tiene como telón no solo la "angustia existencial" proveniente de las generaciones europeas y norteamericanas de la posguerra, sino también los cambios sociales recién iniciados en América Latina, que inician el desmoronamiento de los valores aristocráticos locales y, sobre todo, los primeros movimientos sufragistas en Chile. Estos códigos culturales tenían ejes en común que difuminaban las barreras geográficas de las escritoras, como lo fueron el campo doméstico y la búsqueda del amor como realización personal, presentado como una prisión que sofocaba a personajes sensibles y creativos. Teresa de la Parra publica Ifigenia en 1924, obra con pinceladas feministas, y, posteriormente, en los años treinta se presenta la producción de María Luisa Bombal, para luego llegar a las escritoras del 50, donde todas coinciden con un panorama que incluye protagonistas de clase social acomodada -al igual que las escritoras-, casadas muy jóvenes por razones económicas y con matrimonios desgraciados. A pesar de que son mujeres sensibles, creativas y bellas, no trabajan fuera del hogar y viven una cotidianidad doméstica que deben fisurar con la imaginación. Las

2 En el estudio de Godoy, Ahumada y Díaz, se recopila la recepción crítica de José Donoso, Jaime Laso, Enrique Lafourcade, María Elena Gertner y Margarita Aguirre.

3 Es necesario recordar que la "literatura anterior" es la denominada "neorrealista".

4 La cita muestra la insistencia y molestia de Promis con la crítica por dar una respuesta local a un problema que, para el crítico, no tiene relación con lo extraliterario, sobre todo, con los acontecimientos nacionales. 
escritoras del 50, como vimos previamente, ponen el sexo en la tarima literaria, principalmente mediante el tema de la infidelidad, que llamó mucho la atención, llegando a producir éxitos de ventas como La brecha de Mercedes Valdivieso. Sin embargo, es necesario reconocer que las figuras menos acomodadas de la sociedad ya habían comenzado a aparecer en manera incipiente en el panorama literario. Por ejemplo, en la obra de Marta Brunet, donde las protagonistas deben trabajar para ganarse la vida. En Latinoamérica hay más ejemplos similares en obras calificadas como rurales o "neocriollistas" para desviar el foco a las relaciones de poder de un sistema mayoritario. Este es el caso de Sara Gallardo con la novela Enero (1957), donde la visión utópica del campo es subvertida por la estructura opresora de los jornaleros. Más tarde, el cuento "Modesta Gómez" (1960) de Rosario Castellanos presenta a las mujeres casi en el último escalafón socioeconómico. Por esta razón, es necesario dejar en claro algunos puntos para analizar este periodo.

En primer lugar, debemos cuestionar algunas censuras y eventos que se han impuesto, como aquellas que argumenta Promis, desde un sentimiento existencial de exportación. Es más, muchas de las obras de este grupo se publicaron entre los sesenta y los setenta ${ }^{5}$, como sucede con Mercedes Valdivieso, que publica La brecha en 1961. Sin duda, es importante mover el eje para enmarcar la noción de época a las condiciones históricas, no solo desde la sumatoria de los acontecimientos internacionales, sino desde el campo de las ideas expuestas en ese tiempo.

Claudia Gilman afirma que este periodo contiene un espesor histórico propio que permite identificarlo temporal y conceptualmente. Es un ciclo breve y potente, con coyunturas políticas, intelectuales, estéticas, sociales e institucionales que provocan cambios en el modo de leer y producir discursos sobre la literatura:

La Revolución Cubana, la descolonización africana, la guerra de Vietnam, la rebelión antirracista en los Estados Unidos y los diversos brotes de rebeldía juvenil permiten aludir al haz de relaciones institucionales, políticas, sociales y económicas fuera de las cuales es difícil pensar cómo podría haber surgido la percepción de que el

5 Solo por nombrar algunos de los autores y sus obras más reconocidas están Enrique Lafourcade, Novela de Navidad (1961), Claudio Giaconi, La dificil juventud (1970), José Donoso, Este domingo (1966), María Elena Gertner, La derrota (1965) y La mujer de sal (1967), Margarita Aguirre, La culpa (1964). 
mundo estaba al borde de cambiar y de que los intelectuales tenían un papel en esa transformación, ya fuera como voceros o como parte inseparable de la propia energía revolucionaria (37).

Se trata entonces de un periodo en el que se vive y percibe intensamente político, con el convencimiento absoluto de una transformación radical en todos los aspectos de la sociedad. El despertar de la conciencia sobre los problemas de la dependencia -económica, de género, colonial-afianzó las obras de las escritoras en los cuestionamientos de los problemas políticos en el continente. En este punto hay que subrayar que las escritoras mostraron una intensa preocupación social y participación política, por lo que esta formación de una conciencia -subalterna, de clase, económica, de género, etcétera- es parte de un proyecto emancipador global en el que las escritoras participaron activamente. El acceso de la mujer a la educación y al trabajo fuera de la casa, que venía gestándose desde los inicios del siglo XX, permiten la resignificación del espacio cultural e intelectual con la creciente inclusión de nuevas escritoras y periodistas más "profesionalizadas" ${ }^{6}$ que participaron activamente en el espacio público del debate nacional. Se escribía preferentemente en revistas y editoriales independientes autofinanciadas, que luchaban contra los prejuicios de las publicaciones tradicionales. Es decir, como afirma Montero, "las normas sociales que definían que las lecturas sobre filosofía o política estaban dirigidas a hombres, y la ficción de lo doméstico a las mujeres" (19). Resignificar el espacio, entonces, no solo era el ingreso al campo cultural -como lo entiende Bourdieu-, sino también provocar un malestar, una impostura.

A partir de mediados del siglo XX en Chile ya existían nombres reconocidos en el ámbito literario y cultural ${ }^{7}$, con escritoras como Marta Brunet, María Luisa Bombal, Flora Yáñez y María Carolina Geel, junto a la aparición de las escritoras del 50. Sin embargo, las formas de exclusión, sobre todo desde la crítica, se centraron en la exposición de sus vidas personales, sus comportamientos morales, o focalizándolas en temas propiamente "femeninos",

\footnotetext{
"Las protagonistas de esta historia traspasaron todos los límites que culturalmente habían definido el hogar como el espacio apropiado para ellas, se adentraron en la plaza pública para expresar ideas, opinar sobre el quehacer nacional y, finalmente, para ser" (Montero 13).

Para un análisis más completo del rol de las mujeres en la narrativa chilena de este periodo, véase el trabajo de Andrea Kottow y Ana Traverso, Escribir \& tachar. Narrativas escritas por mujeres en Chile (1920-1950).
} 
a lo cual "ellas responden oscilando entre la autocensura y la destrucción de estos presupuestos masculinos" (Kottow y Traverso 23).

Bajo este escenario aparece La brecha (1961) de Mercedes Valdivieso. Una autora que, a diferencia de otras escritoras agrupadas bajo "la problemática femenina", planteaba en una breve novela el dilema de la existencia femenina en términos concretos y materiales que condujera a un cuestionamiento de las propias estructuras sociales como son el matrimonio, la maternidad y el sexo, haciendo de esta obra la primera con un pensamiento feminista chileno/ latinoamericano consciente (Guerra s/p).

Esta labor de Valdivieso abarcó toda su producción literaria y cultural, creando posteriormente variadas revistas y diarios en los que se destacaba la temática de corte feminista y emancipador ${ }^{8}$ con una visión del mundo más amplia que la visión genérica de la desigualdad entre los sexos, que elabora una crítica a las circunstancias materiales que determinan la vida individual. La visión del mundo de Valdivieso se basa en sólidos principios teóricos, en un profundo sentido de la historia y una conciencia política. En este sentido, ella representa un feminismo que se aleja conscientemente de los modelos europeos y norteamericanos, focalizando la crítica hacia la estratificación social y de clase de las sociedades latinoamericanas.

En una entrevista para de la revista Ercilla, la autora afirma que la misión del escritor en la actualidad es "Denunciar los males de nuestra realidad social, que está en profunda crisis, y abrir nuevos caminos" ("Un Personaje al Trasluz" 11). Desde su lugar de enunciación, Valdivieso se suma a lo que se ha denominado la "fracción crítica" de intelectuales progresistas que se sumaron a una producción literaria estético-ideológica compatible con los

8 Como una investigación pendiente queda el trabajo editorial de Mercedes Valdivieso que no ha sido trabajado ni mencionado por la crítica cultural. En 1966 funda Adán: la revista del hombre latinoamericano, junto a otros escritores e intelectuales como Efraín Barquero y María Elena Gertner. En el primer número se observa el carácter crítico no solo a través de la portada -que mostraba un desnudo de mujer intervenido con dibujos-, sino en el título "La moral no es una púdica virgen" donde afirma: "La moral no es una púdica virgen a prueba de cualquier peligro; la moral va de la mano con la historia y hoy frunce agresivamente el gesto frente a quienes le asignan un carácter inmutable" (63). Con esta declaración de convicción, abre el primer número de la revista.

Beatriz Sarlo sostiene que la figura del intelectual -principalmente de los sesenta-es aquel que entrega valor político a las prácticas intelectuales. Cfr. "Intelectuales, un examen". Revista de Estudios Sociales 5 (2000): 9-12. Web. Consultado el 04 de mayo de 2021. Disponible en: https://revistas.uniandes.edu.co/doi/abs/10.7440/res5.2000.01 
nuevos valores que se promovían. Esta predisposición de los escritores por asumir una responsabilidad política -como afirma Valdivieso en la entrevistaya aparece en un congreso de escritores realizado en Chile en $1960^{10}$, un año antes de la publicación de La brecha.

Debido a las características de la época, y sobre su compromiso político e ideológico, es que observamos en esta primera novela un análisis desapasionado, casi sintético, de la sociedad inspirada en los debates teóricos y sociales de la izquierda de los sesenta/setenta ${ }^{11}$. Utilizando su modelo, es capaz de centrarse en la dinámica del cambio social. Así, en su modelo de pensamiento no hay lugar para abstracciones, las generalizaciones ni recursos intimistas muy propios de las escritoras "femeninas". Entonces, ¿por qué La brecha es considerada la primera novela feminista en Chile y América Latina? ¿Por qué, sesenta años después de su primera publicación, nos convocamos a seguir hablando de ella? Porque, con todo el compromiso político y social, la novela contiene un discurso feminista que debe ser analizado desde una crítica feminista radical, que no analice la obra solo por el hecho de estar escrita por una mujer -que a veces replica el modelo-, sino de realizar un análisis relacionado con acciones y preocupaciones humanas y sociales para descubrir las semejanzas, las discrepancias, lo alterado, borrado, enmascarado y escondido en los códigos impuestos a la literatura, en palabras de Adrienne Rich:

Para la crítica feminista que considera su trabajo como "un empeño con significado social que tiene sus raíces en el 'mundo real"' es esencial contar con una clara comprensión del poder: de cómo la

10 El congreso finaliza con una declaración escrita por Ernesto Sabato, en la cual se afirma que "los escritores no pueden ni debe olvidar la "realidad urgente", la "desdicha y en muchos casos la mísera explotación de los países dominados y explotados" (s/p). Para un análisis más profundo de la figura del intelectual latinoamericano, véase el capítulo "El protagonismo de los intelectuales y la agenda cultural" en Entre la pluma y el fusil: debates y dilemas del escritor revolucionario en América Latina (2012) de Claudia Gilman.

$11 \quad$ En La brecha se puede observar la influencia de Simone de Beauvoir, pero también su conocimiento de autores que se encontraban en el debate intelectual de la época. En un artículo titulado "Sartre dijo "no"" se observa el apoyo y la discusión en torno al rechazo del Premio Nobel del filósofo. Valdivieso rescata seis argumentos de Sartre para negar el premio, afirmando que "Jean Paul Sarte se coloca frente a su conciencia", que es "un hombre comprometido solo con los hechos de su tiempo, sin militancia política" que "ha interpretado con su gesto la opinión de mi pensamientos en silencio" (Valdivieso, "Sartre" 18). 
cultura, tal como la dispensa la universidad, empodera a algunas personas y desempodera a otras; de cómo ella misma puede estar escribiendo desde una posición de privilegio, asociada al color de piel, la heterosexualidad, los antecedentes económicos y educativos, o cualquier otra (479).

Por ello es una obligación revisar los códigos culturales como una práctica para determinar los temas, las restricciones, censuras y exposiciones que abren las posibilidades de relaciones semióticas e histórico-sociales y sus repercusiones. Con estos antecedentes, podemos comprender las respuestas a la aparición de La brecha en el campo literario chileno en 1961 y, posteriormente, con su reedición en 1991. Su primera publicación fue equivalente a lo que hoy llamaríamos un best seller, con cinco ediciones consecutivas en un año. $\mathrm{Su}$ fuerte exposición significó diversas posturas de la crítica, desde aquellos que afirmaron que se trataba de una "escritura con sabiduría [...]. Sus primeros cuatro capítulos, agilísimos, de ritmo cinematográfico, lleno de frases sugerentes y exactas, aprisionan hechos y personajes en una síntesis que envidiaría un escritor experimentado y maduro" (Riera s/p), hasta opiniones como la del Diario Ilustrado, cuyo artículo titulado "Proceso a la morbosidad" afirmaba: "La venta de libros (morbosos) no disminuye: aumenta. Y los escriben, hecho sugerente, mujeres, mujeres que antes no habían hecho aparición alguna en el mundo literario, que mantenían discreto y dibujado silencio. Pero que ahora emergen para contar dramas conyugales, para hablar de 'brechas' y liberaciones, de culpabilidades secretas y secretos de alcoba"12 (cit. en Guerra $\mathrm{s} / \mathrm{p}$ ), nos dice en forma indirecta, sin siquiera nombra la novela.

La recepción de la reedición treinta años después no difiere mucho y, como si el tiempo se hubiese detenido, Carlos Iturra afirma: "La (des)ventaja de -así lo escribiría un crítico amigo- de leer esa protesta de este libro, se encuentra en que la sintetiza y la esquematiza. He aquí la situación de una mujer que, por desgracia, no ama a su marido. Tal es la causa de todo, porque si lo amara... otro gallo cantaría" (38), para luego finalizar con una minimización absoluta de la obra: "Pero sí; algo ha cambiado: la primera vez hubo algún módico escándalo, ahora, ni eso" (ibid.). 
Por esto, sesenta años después de la publicación de La brecha es una obligación literaria y política la revisión y revalorización de esta y otras obras que han permanecido silenciadas en el pasado, sobre todo de aquellas que provocaron incomodidad en algún aspecto de la sociedad.

\section{LA BRECHA EN LOS ESPACIOS INSTITUCIONALES}

Como ya ha analizado previamente la crítica, el abandono de las cuatro paredes domésticas aún denotaba un paso liberador para la protagonista de La brecha, que realiza un agudo examen crítico a la institución familiar. La mujer-personaje anónima del relato declaraba, luego de su decisión de dejar el hogar conyugal: "Empezaba a ensancharse la retina como si me quitaran vendajes de mucho tiempo sobre los párpados. El sol era más amarillo y brillante" (Valdivieso, La brecha 80 ). Con esta afirmación de la protagonista, podemos plantear que La brecha es un relato ficcional político que intenta formar una conciencia libertaria en dos sentidos: una conciencia feminista, que se despliega en la primera mitad de la novela; y una conciencia de clase, presente en la segunda parte. El proceso de formación o Bildungsroman de la protagonista surge cuando la integración armoniosa con su mundo se resquebraja. La protagonista busca una totalidad perdida en un mundo demasiado amplio y estrecho para contener sus deseos que deviene en un reconocimiento de las condiciones de desigualdad y la explotación del ser humano en general, como recuerda la reconocida confesión de la protagonista al inicio del relato:

Me casé como todo el mundo se casa. Ese mundo de horas de almuerzo, del dedo en alto, guardián de la castidad de las niñas. Antes de los veinticinco años debía adquirir un hombre -sine que non-que velara por mí, me vistiera, fuera ambicioso y el que se esperara, al cabo de cierto tiempo, una buena posición: la mejor posible (Valdivieso, La brecha 13).

En la primer parte de la novela, como hemos afirmado, la protagonista -que recordemos, no tiene nombre porque "podría ser cualquier mujer de nuestra generación" (Valdivieso, La brecha 8)- la sujeto del enunciado ya tiene una postura política frente al problema de la mujer y la institución, de ahí su crítica aguda al matrimonio entendido como una transacción comercial 
para elevar la posición familiar. Inicia su relato comprendiendo que su vida es parte de ese brutal mecanismo económico en el que la virginidad, la docilidad, la tradición y la obediencia son características que realzan el valor de las mujeres como objetos de intercambio.

Para Julieta Kirkwood, la perspectiva feminista no se reduce a la participación de las mujeres en la política, sindicatos o gremios, sino de "captar su más profundo significado de constatación frente a un orden tradicionalmente discriminatorio hacia las mujeres" (27). El primer paso, por lo tanto, es desacralizar el análisis de lo femenino. Por ello, en nuestra novela, la primera brecha se abre ante la institución del matrimonio, desmitificando el idilio de la familia burguesa, ya que describe con realismo cómo este supuesto refugio de la felicidad y la realización femenina es un deber, una "adquisición”, como lo explica Emma Goldman:

el matrimonio es un acuerdo económico, un pacto de seguridad. [...] Sin embargo, si la compensación de una mujer es el marido, ella lo paga con su nombre, su intimidad, su propio respeto, toda su vida "hasta que la muerte los separe" [...] El hombre, igualmente, paga su tributo, pero como se mueve en un ámbito más amplio, el matrimonio no lo limita tanto como a la mujer (93).

Asimismo, la comprensión del espacio privado/doméstico es fundamental para "entender la decisiva división entre las esferas pública y privada, entre la esfera de la polis y la de la familia y, finalmente, entre actividades relacionadas con un mundo común y las relativas a la conservación de la vida, diferencia sobre la que se basaba el antiguo pensamiento político como algo evidente y axiomático" (Arendt 42). Además, como ya se ha analizado minuciosamente por la crítica feminista, en la caracterización de estas esferas existe "una invariante estructural que articula las sociedades jerarquizando los espacios: el espacio que se adjudica al hombre y el que se adjudica a la mujer" (Amorós 24). A pesar de las evidentes diferencias históricas, esta distribución de los espacios tiene como característica repetida el que las actividades más valoradas y de mayor prestigio las realicen los hombres.

Por ello, el motivo del encierro y la prisión son fundamentales en las escritoras de esta época. En la primera parte de nuestra novela, el tema del aislamiento está representado por el domicilio conyugal. La joven esposa pronto se siente prisionera de las innumerables prescripciones establecidas por la costumbre. En muchos aspectos, su situación en cuanto a la libertad 
personal ha empeorado desde sus días de soltera. El resultado de esta represión sentida es la aparición de un estado depresivo que acompaña a la heroína durante la mayor parte de su vida de casada: "Deje de pertenecerme por fuera y me amurallé por dentro. La libertad esperada ingenuamente a vuelta del contrato matrimonial se hacía lejana. ¿Era mejor esto que la severidad de mi madre?" (Valdivieso, La brecha 21). Esta sensación empeora con el primer embarazo inesperado y no deseado: "No podía resignarme. El calor de esa tarde de marzo, denso, pesado, se hizo un círculo que me envolvía y del que no podía liberarme. Todo estaba obscuro dentro de mí [...] el embarazo era un nudo de angustia y desolación (Valdivieso, La brecha 24), cuestionando, de este modo, la identidad ontológica maternal de las mujeres cuando no se trata de una elección personal ${ }^{13}$.

En La brecha, la intención es clara y directa desde el principio. Por ello, la crítica a la institución del matrimonio conlleva un desenmascaramiento de los símbolos religiosos para desmitificar el aspecto religioso de la existencia humana. El demonio se presenta desprovisto de toda connotación negativa y es asociado a la figura del padre de la protagonista, con quien comparte el inconformismo y rebeldía: "Eres como yo, un poco hijo del Diablo; pero no hay que temerle, es positivo, todo el progreso se lo debemos a él" (Valdivieso, La brecha 2). Por otro lado, como otra forma de crítica al sistema patriarcal, las mujeres son las principales defensoras de las ideas convencionales con respecto a su papel: su madre, su abuela y su suegra: "Eres mujer y aprenderás a zurcir y a estar quieta; nadie querrá que a los diez días de casada, te devuelvan por inútil" (Valdivieso, La brecha 14). En este sentido, Valdivieso también desmitifica la familia como institución de apoyo a la liberación individual de la mujer. Así, el relato subraya temas antes prohibidos, como el aburrimiento femenino, la crítica al cónyuge, la infidelidad, el aborto y, por último, incluso los diversos detalles relacionados con el proceso de obtención del divorcio en

13 El tema de la maternidad ha sido fundamental por las diversas posturas feministas que hasta ahora se debaten en temas como el aborto y el derecho al cuerpo. Como si el tiempo no avanzara en este tema, debemos recordar que cuando Lina Meruane publica Contra los hijos (2014) -que incluye afirmaciones como esta: "en el tener-hijos no solo persiste el llamado biológico (el proverbial reloj haciendo saltar su insoportable tictac) sino que a este se añade la insistente alarma del dictado social: se suman las hormonas los discursos de reproducción haciendo que el mandato materno se vuelva difícil de esquivar" (21)-, puso el dedo en la llaga mística de la maternidad con un tono tan directo y áspero como lo hizo Valdivieso en su primera novela. 
un país en el que solo se contemplan los factores subjetivos de la existencia femenina -lo afectivo, el exceso de indulgencia con los sentimientos-, ya que se muestra a una mujer que explora ámbitos del quehacer humano antes vedados.

El divorcio y la independencia económica son el leitmotiv que atraviesa esta primera parte. Como lectores, ansiamos el éxito de la protagonista y la acompañamos en su proceso. Para ello somos testigos de las grandes limitaciones que conllevan esta decisión y que permanecen tan actuales. Estos obstáculos tienen dos categorías generales: por un lado, las tradicionales de la época que provocan la sanción de la sociedad; y, por otro, las más actualizadas, cuando las mujeres intentan salirse de los roles tradicionales y se encuentran también encadenadas en sus ámbitos laborales, mostrando la figura de la mujer separada, sola o divorciada que trabaja para mantener a sus hijos tan reconocida actualmente. Esta doble categorización de los obstáculos para la independencia de la protagonista es lo que mantiene a La brecha como una obra feminista actual, pero que además da un paso más allá de la sola crítica del género, adentrándose también en la condición deshumanizante del sistema, como afirma la misma protagonista una vez que ha conseguido el divorcio y la independencia económica:

"Ganarás el pan con pan con el sudor de tu frente". La terrible maldición de Dios al hombre caído. Y a la mujer "Parirás tus hijos con dolor". Sorbí el café con infinita resignación: "Ambas maldiciones me tocan" (Valdivieso, La brecha 113).

El divorcio, junto con el paso de la esfera privada al mundo laboral, lleva a la protagonista a un desalentador descubrimiento: los mecanismos opresivos que ella identificaba con la dinámica conyugal se extendían más allá de los confines domésticos.

\section{LAS BRECHAS TEXTUALES}

La crítica -y la academia en general-analizan las obras desde una dimensión canónica y de valor de la obra que incluye género literario, punto de vista, lenguaje, entre otras. El primer paso, entonces, para indagar desde una crítica feminista consiste en identificar las obras que, en el momento de su publicación, fueron leídas "por criterios androcéntricos que de manera 
consciente o inconsciente buscaban mantener el predominio masculino sobre los espacios culturales y literarios" (Pratt 71). El segundo paso es cuestionar los procesos de validación literaria que establecieron estas exclusiones, siendo uno de ellos la escritura misma.

La brecha, como hemos comentado, no solo produjo comentarios por su contenido, sino también por la forma y tono. Es un relato directo, sobrio, frívolo, como afirmaron algunos críticos de la época, porque no hay muestras de una pasión desgarradora, sino un intento deliberado de evitar el mecanismo de evasión y solipsismo muy común en las escritoras de la época ${ }^{14}$. El uso de la primera persona permite la coincidencia del sujeto de la enunciación con el del enunciado, por medio de un "yo plural" que la voz narrativa marca desde el inicio del relato: "El personaje de esta novela no tiene nombre, pero podría ser el de cualquier mujer de nuestra generación" (Valdivieso, La brecha 8). El discurso entonces asume un "yo social" que condensa, en palabras de Arfuch, los "tonos de la época": "la compulsión de realidad, la autenticidad, lo 'directo', la presencia" (23). El tono con que la voz narrativa cuenta su historia también refuerza la impresión de que ha emprendido una empresa noble. Con este lenguaje controlado, cuenta la historia de una batalla silenciosa y valerosamente librada. Esta exaltación atenuada es evidente en el siguiente pasaje en que la protagonista compara su situación con la de su de su actual amante: "Ambos hemos vivido, lo que equivale a decir, hemos padecido. Pero no ha fracasado, no ha conocido, ni oído, como yo, el estrépito de la represa que se rompe ni la lucha por sostenerse después, braceando en la corriente para sobrevivir" (Valdivieso, La brecha 141). Lo interesante de este pasaje es que, aunque la lucha no se minimiza, la voz narrativa no adorna el discurso para ganarse la simpatía de una causa que no está justificada racionalmente. Además, se puede detectar en el tono la intención de proporcionar un modelo de acción para otros atrapados en el mismo dilema.

14 Como ejemplo de este tipo de escritura podemos compararla con María Elena Gertner en La mujer de sal (1964): "Voy a contar la historia de tu amor, de nuestro amor, y nuevamente veo resplandecer todo frente a mí. Cuando cuente la historia de tu desamor, habré llegado al término. Hoy tengo otra vez veintinueve años. Te he conocido ayer y me has besado. No he dormido anoche. La sensación de tu boca sobre mi boca me perseguía; y también tus manos, y el sonido de tu voz prolongándose en innumerables vibraciones a través de la casa y de mi jardín silencioso" (181). Es interesante la relación entre el deseo y la escritura que se presenta como un deseo obsesivo de contarlo todo: "El deseo es el reconocimiento de la falta, posibilitando, no obstante, el encuentro consigo, a través de la aceptación de la entrega al otro" (Kottow y Traverso 146). 
La narración en primera persona permite a la voz enunciativa no solo relatar los acontecimientos que condujeron a un matrimonio fracasado, la oposición de las sanciones sociales, de las amonestaciones religiosas y de las complicaciones legales, sino que, lentamente, en el plano de las circunstancias, en otro nivel de conciencia, hay un camino similar de progreso adquirido con respecto a su problemática y que, como lectores, observamos por el uso de las digresiones. Aunque la narración en primera persona no permite el comentario directo del autor/a de las acciones de la protagonista, su estrecha identificación de este con el personaje elimina la distancia entre el sujeto de la enunciación y del enunciado, permitiendo la conformación de un discurso narrativo, no de un "yo" intimista, sino de una experiencia colectiva. Se trata de un "sujeto encarnado" (Arfuch 23) en personajes reales -"cualquier mujer de nuestra generación"-, que representa una amplia posibilidad de sujetos reales en tiempos diferentes. Por ello la vigencia de esta novela. La narración en primera persona permite a la autora mostrar de primera mano las distintas etapas de la evolución en la conciencia y su posición política frente al acontecimiento. Por ello, en la novela se abre una brecha que permite el ingreso del "ensayo de género" como forma de reflexión.

Para Mary-Louise Pratt, el "ensayo de identidad" es la columna vertebral de canon literario latinoamericano, escrito por grandes pensadores que se preguntaban “¿cómo representar nuestra hegemonía? ¿En qué consiste -o en que debe consistir- nuestro proyecto social y cultura?" (74). Las respuestas a estas grandes preguntas han venido del intelectual masculino, blanco y de origen euroamericano ${ }^{15}$, pero no de mujeres intelectuales que han sido restringidas del ámbito de las "bellas letras" a pesar de ser escritoras pertenecientes a una élite social y política. El "ensayo de género" es un corpus textual de "una serie de textos escritos por mujeres latinoamericanas [...] enfocados al estatuto de las mujeres en la sociedad" $(76)^{16}$. Se trata de una literatura para desafiar la hegemonía masculina de la cultura, la literatura, las artes y la historia relacionadas con la figura de la intelectual pública, que escribe

15 Pratt afirma que cualquiera puede recordar con facilidad a los exponentes del ensayo latinoamericano: Simón Bolívar y "Carta de Jamaica", Sarmiento con Facundo, Martí y Nuestra América, Mariátegui y Los siete ensayos, Octavio Paz con El laberinto de la soledad, Fernández Retamar y Calibán, entre otros.

16 Pratt recoge los cientos de ensayos y autoras desde el proceso de fundación latinoamericana. 
obras de ficción, pero también participa activamente por medio de la prensa en asuntos públicos, como es el caso de Mercedes Valdivieso.

El "sujeto encarnado" - como afirmamos previamente- se observa a través de la construcción narrativa dentro de un espacio íntimo por medio de la reflexión autobiográfica que se funde en una relación con lo externo. La corriente de la conciencia como construcción sintáctica sin orden es reemplazada por digresiones lógicas, ordenadas, concisas y sincrónicas que van permeando el relato ficcional para incluir percepciones sobre su problemática y la propia visión del mundo de la autora con respecto al cambio radical de las estructuras sociales. La voz que abre esta brecha es un acto de habla que pone en sentido la vivencia personal sin importar si se está justificando, confesando o testimoniando. El acto de habla de "afirmar" es el que abre el relato: "me casé como todo el mundo se casa" (Valdivieso, La brecha 13) ubicándonos como lectores en ese lugar de enunciación. El relato se desarrolla como ya lo conocemos -separación, aborto, divorcio y trabajo-, tejido por estas digresiones que van formando una crítica no solo a la condición subordinada de la mujer, sino al sistema entero. Algunos ejemplos se encuentran al inicio de la narración, cuando la protagonista, recién casada, se cansa de nadar en un lago y el marido le dice "¡Te gané!": "Yo apretaba los dientes y volvía a la orilla. Jamás aceptaría supremacía de ninguna clase. La competencia surgía como un duende con las manos escondidas en la espalda" (Valdivieso, La brecha 19) para criticar la competitividad hasta en el matrimonio. También incorpora variables personales-comunitarias, conceptuales e históricas que hacen que el lector/a sea partícipe de opinión en hechos contingentes, como relata la protagonista en una de las cenas con los amigos de su marido, mientras se hablaba de economía y uno de los invitados afirma:

El subdesarrollo no existe en forma material, lo que existe es la inconformidad cuando se han conocido otras formas de vida superiores. Los pueblos de un sitio perdido en el globo pueden estar perfectamente, mientras no ponen en contraste su realidad con la que creen podría ser. [...] Ciertos países, como ciertas personas, viven soñando con lo que no pueden tener, en vez de someterse a la voluntad divina, tratando, dentro de sus posibilidades, de alcanzar algo mejor (Valdivieso, La brecha 52) ${ }^{17}$.

17 Este fragmento llamó la atención de Ángel Rama sobre esta novela, quien afirmó que "logra recomponer con un permanente interés un tema ya trillado, y tipificar en una historia 
Frente a esta afirmación, la protagonista le responde: "Usted no habla en serio. ¿Con qué derecho se burla de los estafados de la tierra? ¿Por qué yo tengo que oírle tanta gratuita estupidez?" (ibid.). Para Paul Ricoeur, el proyecto identitario y el eje de la narración se reconoce como una "concordancia discordante" que asume los acontecimientos y las irrupciones imprevistas como momentos constitutivos de la identidad (138) -aquella que Arfuch llama "encarnada" - con el mundo por medio del "cuerpo entre cuerpos, [que] constituye un fragmento de la experiencia del mundo" (129). La identidad narrativa se basa, por lo tanto, en la diferencia entre estas dos identidades por medio de la interlocución con el otro que se configura en la estructura de una narración permeable que debe admitir los cambios constitutivos de la identidad. La respuesta directa de la protagonista es posible porque la brecha textual permite filtrar el tiempo de la narración (la cena con los amigos), el tiempo de la vida (la discusión sobre el subdesarrollo) y la propia experiencia (la posición política de la autora). En esta fisura aparecen los puntos éticos, políticos y estéticos como posición enunciativa, espacial, temporal y afectiva para dar significado al acontecimiento de la historia. Se convierte así en una postura ideológica que trasciende cualquier incorregibilidad puramente personal con un cónyuge. Su discusión, en última instancia, es con todo un sistema de valores, con todo un orden mundial.

Esta digresión tendrá mayor sentido en la segunda parte de la novela, cuando la protagonista ingresa al mundo del trabajo y entiende "en carne propia" esa crítica a la pobreza. Es aquí donde comienza la segunda fase de su toma de conciencia, cuando alcanza la autonomía civil, pero no la libertad. En primer lugar, se da cuenta rápidamente de que, con sus escasas habilidades de secretaria, la única manera de conseguir un trabajo es recurrir a algunos viejos contactos financieros de su padre. Luego entiende que su insignificante trabajo, sus escasos momentos para ella y su pertenencia a una fuerza de trabajo alienada representan una libertad muy parcial. Rápidamente, entiende que esta liberación no puede obtenerse a nivel individual, como había sido posible con su matrimonio opresivo, sino que se enfrenta a un orden económico inexorable que reduce a las personas a objetos y las domina, explotando su miedo a la supervivencia: 
Recorría las oficinas y observaba a los muchachos inclinados en sus escritorios, totalmente sometidos. La canalización de sus vidas era tan definitiva, que apartarlos de la obediencia y la obligación sería dejarlos botados. Se movían dentro del terrible molde que ha conformado sus cerebros (Valdivieso, La brecha 133).

La protagonista ha entendido, como afirmara Kirkwood, que formar la conciencia de que "la constitución de un proyecto político total será también a partir de las marginalidades, una de las cuales la constituyen las mujeres. El camino hacia la inclusión social [...] desde todos los sectores excluidos, en una redimensión de los tiempos, los espacios sociales y políticos" (29). Así, la sujeto de la enunciación ha sido capaz de distinguir la estructura social más allá de lo personal e identificarse entre las víctimas del sistema brutal que impide el desarrollo personal: "Abajo en la calle, una muchacha se bajaba apresuradamente de un taxi y se abalanzaba a una puerta. Desde la maldición de Dios golpeaba el imperativo: ‘¡Trabaja!' Para la mayoría, sin sentido, sin entusiasmo, por deber, no por conciencia de futuro: trabaja" (Valdivieso, La brecha 128).

Desde esta postura crítica ha contado su historia. Hacia el final de la novela, elabora una defensa a favor de la liberación de todas las personas. Por el momento, todo el fervor revolucionario se ha apagado, ya que ella también debe luchar por la supervivencia diaria. Aunque admite la necesidad de una relación humana, no está dispuesta a renunciar tan fácilmente a lo que ha ganado con tanta lucha. La cuestión queda abierta, sin resolver. La conclusión evita el final convencional en el que la protagonista se encuentra junto a un protector masculino, sino que ha adquirido una conciencia crítica $y$, con ello, una gran angustia al comprender la urgente necesidad de un cambio social. Por último, la novela ha acogido a toda la sociedad en su motivo de encierro, indicando la necesidad de trabajar por la liberación de todos. La victoria de la protagonista es solo parcial y relativa, mientras no exista un cambio profundo en el sistema social completo.

De este modo, la salida que se creía definitivamente emancipadora conllevaba una ambivalencia condensada en la imagen de una sociedad carcelaria:

Soy como un recluso que hizo saltar la cerradura de su calabozo y a quien después de ciertas escaramuzas, le está permitido pasearse por la enorme cárcel, conversar con los presos en sus celdas y luego sentarse a esperar frente a la puerta (Valdivieso, La brecha 142). 
En conclusión, La brecha es una novela que sorprendió hace sesenta años por la audacia de sus afirmaciones y que, sin embargo, mantiene intacta las mismas demandas de igualdad y crítica social a un sistema que no ha cambiado en seis décadas las mismas prácticas de desigualdad y discriminación.

Con su primera novela, Mercedes Valdivieso se erige como una de las intelectuales latinoamericanas más importantes, que tomó una posición política en una década de cambio radical en la que se requerían -tal y como aún se requieren-compromisos políticos. La brecha es precisamente lo que nombre indica: una fisura que le permitirá a Mercedes Valdivieso continuar con la labor de la protagonista de su propia novela en el compromiso intelectual y político hacia una sociedad menos desigual.

\section{BIBLIOGRAFÍA}

Amorós, Celia. Feminismos, igualdad y diferencia. Ciudad de México, Universidad Autónoma de México/PUEG, 1994.

Arendt, Hannah. La condición humana. Buenos Aires, Paidós, 2005.

Arfuch, LeOnor. El espacio biográfico. Dilemas de la subjetividad contemporánea. Ciudad de México, Fondo de Cultura Económica, 2002.

Castellanos, Rosario. Obras Reunidas II. (Cuentos). Ciudad de México, Fondo de Cultura Económica, 2005.

Gallardo, Sara. Enero. Buenos Aires, Editorial Sudamericana, 1958.

Gertner, María Elena. La mujer de sal. Santiago, Zig-Zag, 1964.

Godoy, Eduardo, Haydée Ahumada Peña y Carlos Díaz Amigo. La generación del 50 en Chile: historia de un movimiento literario. Santiago, Editorial La Noria, 1992.

Goldman, Emma. La palabra como arma. Buenos Aires, Terramar, 2010.

GuERRA, LuCíA. Escritoras latinoamericanas: hacia una identidad propia (inédito). Manuscrito facilitado por la autora.

Iturra, Carlos. "El divorcio femenino". Revista Ercilla, 11 de septiembre de 1991, p. 38.

Kirkwood, Julieta. Ser politica en Chile. Las feministas y los partidos. Santiago, LOM ediciones, 2017.

Kottow, Andrea y Ana Traverso. Escribir \& tachar. Narrativas escritas por mujeres en Chile (1920-1970). Santiago, Overol, 2020.

"La moral no es una púdica virgen". Adán: La revista del hombre latinoamericano, 30 de noviembre de 1966, 7, p. 63.

Meruane, Lina. Contra los hijos. Santiago, Penguin Random House, 2014.

Montero, Claudia. Y también hicieron periódicos. Cien años de prensa de mujeres en Chile 1850-1950. Santiago, Hueders, 2018. 
Pratt, Mary-Louise. "No me interrumpas': las mujeres y el ensayo latinoamericano". Debate Feminista 21, 2000, pp. 71-78.

Promis, José. La novela chilena actual: orígenes y desarrollo. Buenos Aires, F. García Cambeiro, 1977.

RAMA, ÁNGEL. La querella de realidad y realismo. Ensayos sobre literatura chilena. Santiago, Mímesis, 2018.

Rich, Adrienne. Ensayos esenciales. Cultura, politica y el arte de la poesía. Madrid, Capitán Swing, 2019.

Ricoeur, Paul. Sí mismo como otro. Ciudad de México, Siglo XXI, 1996.

Riera, Alfonso. "Mercedes Valdivieso: 'La brecha”. El Siglo, 25 de junio de 1969.

Sabato, ERnesto. "Sobre un congreso". El Clarín, 14 de febrero de 1960.

"Un Personaje al Trasluz. Autora de 'La Brecha': No soy la protagonista”. Revista Ercilla, 26 de julio de 1961, p. 11.

VAldivieso, Mercedes. La brecha. Santiago, Zig-Zag, 1961.

"Sartre dijo 'no"”. Revista Zig-Zag, 30 de octubre de 1964, p. 18. 